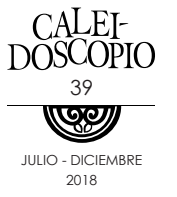

\title{
El sí-mismo social ${ }^{1}$
}

GEORGE HERBERT MEAD

Traducción: Miguel A. Sahagún Padilla² y Anna Vitores González ${ }^{3}$

Reconociendo que el sí-mismo ${ }^{4}$ no puede aparecer en la consciencia como un "yo", que siempre es un objeto, i.e. un "mi", me gustaría proponer una respuesta a la pregunta ¿qué implica que el sí-mismo sea un objeto? La primera respuesta podría ser que un objeto implica un sujeto. Dicho en otras palabras, que un "mi" es inconcebible sin un "yo". Y a esto hay que responder que dicho "yo" es una presuposición, pero nunca una presentación de experiencia consciente, dado que una vez que se presenta, ha pasado ya al modo objetivo, suponiendo, si se quiere, un "yo" que observa -pero un "yo" que se revela a él mismo sólo en tanto que cesa de ser el sujeto para el cual el objeto "mi" existe. No es que esté interesado, por supuesto, en el hegelianismo de un sí-mismo que se convierte en otro para él mismo, sino en la naturaleza del sí-mismo tal como se revela mediante introspección, sujeto a nuestro análisis factual. En un proceso de memoria, este análisis pone de manifiesto una actitud de observación de uno mismo en la que ambos, el observador y lo observado, aparecen. Para ser concreto, uno

1 Publicación original: Mead, G. H. (1913). The Social Self. Journal of Philosophy, Psychology, and Scientific Methods, 10, 374-380. Recuperado de: http://psychclassics.yorku.ca/Mead/socialself.htm.

2 masahagun@correo.uaa.mx.

3 anna.vitores@gmail.com.

4 Optamos por traducir los términos self y selves por "sí-mismo" y "sí-mismos", respectivamente, con el fin de distinguirlos de la traducción de expresiones como himself o itself. 
recuerda preguntarse a uno mismo cómo podría emprender esto o aquello, reprendiéndose uno mismo por sus fallos o vanagloriándose por sus logros. De este modo, es en el sí-mismo restablecido del momento que ya pasó que uno encuentra a ambos, un sujeto y un objeto, pero se trata de un sujeto que ahora es un objeto de observación, con la misma naturaleza que el sí-mismo objeto que presentamos como en relación con quienes tenemos alrededor nuestro. Exactamente de la misma forma recordamos las preguntas, advertencias y consentimientos que se nos dirigen. Pero la actitud de sujeto que adoptamos instintivamente sólo puede ser presentada como algo experimentado -del mismo modo que sólo podemos ser conscientes de nuestros actos a través de los procesos sensoriales puestos en marcha después de que el acto ha comenzado.

Los contenidos de este sujeto presente, el que entonces ha devenido objeto al ser presentado, pero que aún se distingue como el sujeto de la experiencia pasada respecto al "mí" al que se dirige, son aquellas imágenes que iniciaron la conversación y las sensaciones motrices que acompañan la expresión, además de las sensaciones orgánicas y la respuesta de la totalidad del sis- tema a la actividad iniciada. El sí-mismo apareciendo como "yo" es la imagen del sí-mismo en la memoria, actuando hacia él mismo, y es el propio sí-mismo actuando hacia otros sí-mismos.

Por otro lado, aquello que define el "mí" a quien el "yo" se dirige y observa es la experiencia inducida por la acción del "yo". Si el "yo" habla, el "mí" escucha. Si el "yo" golpea, el "mí" siente el golpe. De nuevo, la consciencia del "mí" tiene el mismo carácter que aquella que surge de la acción del otro sobre sí. Es sólo en tanto que el individuo se encuentra actuando respecto a él mismo como actúa hacia los otros, que se convierte en sujeto para él mismo y no en objeto; sólo en tanto que es afectado por su propia conducta social en el modo en que es afectado por la de otros, es que deviene objeto de su propia conducta social.

Las diferencias en las presentaciones del "yo" y del "mí" en nuestra memoria son las diferencias entre las imágenes de la conducta social iniciada y aquellas de la respuesta sensorial a dicha conducta. Considerando los análisis de Baldwin, Royce, Cooley y muchos otros, no tiene caso más que indicar que esas reacciones surgen en nuestra conducta social con los otros, antes que en nuestra consciencia-de-sí intros- 
pectiva. Por ejemplo, el infante llama la atención de los otros de forma consciente antes de llamar su propia atención, afectándose él mismo; el infante es conscientemente afectado por los otros antes de que sea consciente de ser afectado por él mismo.

El "yo" de la introspección es el sí-mismo que se involucra en relaciones sociales con otros sí-mismos. No es el "yo" que está implicado en el hecho de presentarse uno mismo como "mí". Y el "mí" de la introspección es el mismo que el "mí" que es el objeto de la conducta social de otros. Uno se presenta a uno mismo como actuando hacia otros -en esta presentación, él es presentado en discurso indirecto como el sujeto de la acción y aún es un objeto- y el sujeto de esta presentación no puede aparecer nunca de forma inmediata en la experiencia consciente. Es el propio sí-mismo el que es presentado como observándose él mismo y se afecta él mismo sólo en la medida en que puede dirigirse a él mismo a través de los medios de estimulación social que afectan a los otros. El "mí" a quien él se dirige es entonces el "mí" que, de forma semejante, es afectado por la conducta social de quienes tiene alrededor.

Sin embargo, esta afirmación sobre la situación introspectiva parece pasar por alto una pro- piedad más o menos constante en nuestra consciencia: ese percatarse fluidamente de lo que hacemos, que es distinguible de la consciencia del campo de estimulación, sea que dicho campo esté dentro o fuera. Es este "darse cuenta" el que ha llevado a varios a asumir que la naturaleza del sí-mismo es ser consciente de sujeto y de objeto -ser sujeto de acción hacia un mundo de objetos y, al mismo tiempo, ser directamente consciente de este sujeto como sujeto-, "Pensando su no-existencia junto con lo que sea que ello piense".

Ahora bien, como el profesor James ha señalado, esta consciencia se concibe de forma más lógica como "sciencia" -siendo el pensador una implicación en vez de un contenido, mientras que el "mí" es apenas una pizca de contenido de objeto en el flujo de "sciencia". No obstante, esta afirmación lógica no hace justicia a los hallazgos de la consciencia. Además de las estimulaciones y respuestas presentes, y de las imágenes de éstas en la memoria, dentro de las cuales se encuentran forzosamente las sensaciones y respuestas orgánicas que constituyen el "mí," acompaña ahí una buena parte de la experiencia consciente todo aquello que llamamos consciente-de-sí, una respuesta interna a aquello 
que podríamos estar haciendo, diciendo o pensando. Dentro de nuestras cabezas, buena parte del tiempo somos más o menos claramente conscientes de nuestras propias respuestas a los comentarios hechos a otros, de inervaciones que conducirían a actitudes y gestos respondiendo nuestros gestos y actitudes hacia otros.

El observador que acompaña toda nuestra conducta consciente-de-sí no es entonces el verdadero "yo", responsable por la conducta in propria persona -él es más bien la respuesta que uno genera respecto a su propia conducta. La confusión a esta respuesta nuestra, que se sigue de nuestras estimulaciones sociales de otros con el sujeto implícito de nuestra acción, es la base psicológica para asumir que el sí-mismo puede ser directamente consciente de sí como actuante y como objeto de acción. En realidad, la situación es ésta: el sí-mismo actúa en referencia a otros y es inmediatamente consciente de los objetos alrededor de él. En la memoria, reintegra además al sí-mismo actuando, así como a los otros sobre los que se actúa. Pero, aparte de estos contenidos, la acción en referencia a los otros reclama respuestas en el propio individuo -hay otro "mí" criticando, aprobando, sugiriendo y planificando conscientemente, i.e. el sí-mismo reflexivo.

No es entonces que respondamos a toda nuestra conducta hacia el mundo objetivo. Ahí donde estamos intensamente preocupados con el mundo objetivo, este darse cuenta que nos acompaña, desaparece. Tenemos que recordar la experiencia para darnos cuenta de que hemos estado implicados como sí-mismos, para producir la consciencia-de-sí, que es una parte constituyente de una gran parte de nuestra experiencia. Como ya he señalado en otro sitio, el mecanismo para esta respuesta a nuestra propia estimulación social de otros ocurre como un resultado natural del hecho de que los mismos sonidos, gestos especialmente gestos vocales- que el hombre hace al dirigirse a otros, reclaman o tienden a reclamar respuestas de él mismo. No puede escucharse él mismo sin asumir, en alguna medida, la actitud que él habría asumido si otros le hubieran dirigido las mismas palabras.

El sí-mismo que conscientemente se enfrente a otros sí-mismos deviene entonces objeto, un otro para él mismo, a través del mismo hecho de que se escucha él mismo hablar y responder. El mecanismo de introspección está entonces dado en la actitud social que el hombre necesariamente asume hacia él mismo, y el 
mecanismo de pensamiento, en la medida en que el pensamiento usa símbolos que son usados en las relaciones sociales, no es más que una conversación interior.

Ahora bien, es justo esta combinación del sí-mismo recordado, que actúa y existe en oposición a otros sí-mismos con la respuesta interna a su acción, la que es esencial para el ego consciente-de-sí -el sí-mismo en toda la extensión de la palabra-, aunque ningún momento de la consciencia-de-sí, en tanto que aparece como un objeto de nuestra experiencia, es un sujeto.

Debería notarse, además, que esta respuesta a la conducta social del sí-mismo podría darse en el rol de otro - presentamos sus argumentos en la imaginación y lo hacemos con sus entonaciones y gestos, incluso quizá con su expresión facial. De este modo, adoptamos los roles de todo nuestro grupo; en verdad, es sólo en la medida en la que hacemos esto que ellos se convierten en parte de nuestro ambiente social -darse cuenta de otro sí-mismo como un sí-mismo implica que hemos adoptado su rol o el de otro, con cuyo tipo lo identificamos para los propósitos de la relación social.

La respuesta interna a nuestra reacción a los otros es entonces tan variada como nuestro am- biente social. No es que adoptemos los roles de otros hacia nosotros mismos porque estemos sujetos a un mero instinto imitativo, sino porque al responder a nosotros mismos, solemos estar tomando la actitud de otro distinto al sí-mismo que está actuando directamente, y es hacia esta reacción que fluyen naturalmente las imágenes de la memoria de las respuestas de aquellos alrededor nuestro, las imágenes de la memoria de aquellas respuestas de otros surgidas como contestación a acciones semejantes. Así, el niño puede pensar sobre su conducta en tanto que buena o mala sólo cuando reacciona a sus propios actos en el recuerdo de las palabras de sus padres. Hasta que este proceso se desarrolla como proceso de pensamiento abstracto, la consciencia-de-sí permanece dramática, y el sí-mismo, que es una fusión del actor recordado y del coro que lo acompaña, se encuentra laxamente organizado y muy claramente social. Después, la etapa interior se transforma en el foro y el taller del pensamiento. Las propiedades y entonaciones de la dramatis personae se desvanecen y el énfasis recae sobre el sentido del habla interna; la imaginería se transforma meramente en la señal apenas necesaria. Pero el mecanismo sigue siendo social $y$, en 
cualquier momento, el proceso puede volverse personal.

Es apropiado afirmar que, últimamente, el mundo occidental moderno ha hecho mucho de su pensar en forma de novela, mientras que, anteriormente, el drama era un mecanismo de conciencia-de-sî́ más efectivo, pero igualmente social. Y, de paso, podría referirme a esa necesidad de engordar al flaco portavoz del pensamiento abstracto, que incluso el pensador más abstruso siente al buscar su público. La importancia de eso para la consciencia-de-sí religiosa es evidente.

Hay una implicación más de esta naturaleza del sí-mismo sobre la cual deseo llamar la atención. Es la manera de su reconstrucción. Deseo especialmente referirme a ella porque el asunto es importante en la psicología de la ética.

En tanto que mera organización de hábito, el sí-mismo no es consciente-de-sí. Es el sí-mismo al que nos referimos como personaje. Sin embargo, cuando aparece un problema esencial, hay alguna desintegración en esta organización; diferentes tendencias aparecen en el pensamiento reflexivo como diferentes voces en conflicto unas con otras. En

5 Self-consciousness se tradujo como "conciencia-de-sí". cierto sentido, el viejo sí-mismo se ha desintegrado y un nuevo sí-mismo emerge del proceso moral. La pregunta específica que deseo hacer es si el nuevo sí-mismo aparece junto con el nuevo objeto o fin. Existe, por supuesto, una relación recíproca entre el sí-mismo y su objeto, uno implica al otro y los intereses y evaluaciones del sí-mismo contestan con exactitud al contenido y valores del objeto. Por otra parte, la consciencia del nuevo objeto, sus valores y sentido parecen llegar más temprano a la consciencia, que el nuevo sí-mismo que contesta al nuevo objeto.

El hombre que ha llegado a darse cuenta de un nuevo valor humano se percata más inmediatamente del nuevo objeto en su conducta que de él mismo y su forma de reacción al objeto. Esto se debe al hecho que ya se había referido: la atención directa va primero al objeto. Cuando el sí-mismo deviene objeto, aparece en la memoria, y la actitud que implicaba ya ha sido tomada. De hecho, distraer la atención del objeto para el sí-mismo implica justo esa falta de objetividad que criticamos no sólo en el agente moral, sino en el científico.

Asumiendo, como hago yo, el papel esencialmente social del fin ético, en la reflexión moral encontramos un conflicto en el que 
ciertos valores hallan un vocero en el viejo sí-mismo o una parte dominante del viejo sí-mismo, mientras que otros valores que responden a otras tendencias e impulsos surgen en oposición y encuentran otros voceros que presenten sus causas. Abandonar el campo a los valores representados por el viejo sí-mismo es exactamente lo que llamamos egoísmo. La justificación del término se encuentra en el tipo de conducta habitual con referencia a esos valores. La atención no es reclamada por el objeto y se desplaza luego al campo subjetivo, donde las respuestas afectivas se identifican con el viejo sí-mismo. El resultado es que declaramos los otros fines conflictivos en términos subjetivos de otros sí-mismos y el problema moral parece adoptar la forma del sacrificio, sea del sí-mismo o de los otros.

De cualquier modo, cuando el problema es considerado objetivamente, aunque el conflicto es social, no debería resolverse en una lucha entre sí-mismos, sino en una reconstrucción de la situación tal, que personalidades, diferentes, ampliadas y más adecuadas puedan emerger. Una tensión debería centrarse en el campo social objetivo.

En el análisis reflexivo, el viejo sí-mismo debería entrar en los mismos términos con los sí-mis- mos cuyos roles son asumidos, y la prueba de la reconstrucción se encuentra en el hecho de que todos los intereses personales son reconocidos adecuadamente en una nueva situación social. El nuevo sí-mismo que responde a esta nueva situación puede aparecer en la consciencia sólo después de que esta nueva situación ha sido entendida y aceptada. El nuevo sí-mismo no puede entrar en el campo como el factor determinante porque se hace conscientemente presente sólo después de que el nuevo fin ha sido formulado y aceptado. El viejo sí-mismo podría entrar sólo como un elemento frente a los otros intereses personales involucrados. Si él es el factor dominante, debe serlo en desafío a los otros sí-mismos, cuyos intereses están en juego. Él es definido como el viejo sí-mismo por su conflicto con los otros, que se afirman ellos mismos en su análisis reflexivo. La solución se alcanza a través de la construcción de un nuevo mundo que armonice los intereses en conflicto en los que entra el nuevo sí-mismo.

En su lógica, el proceso es idéntico al abandono de la vieja teoría con la que el científico se ha identificado; su negativa a conceder a esta vieja actitud algún peso más que pudiera darse a las otras observaciones e hipótesis en conflicto. Sólo cuando 
una hipótesis exitosa que supera los conflictos ha sido formulada y aceptada, puede el científico de nuevo identificarse él mismo con la hipótesis como suya y mantenerla contra mundum. Él puede no declarar el problema científico y su solución en los términos de su vieja personalidad; puede llamar a su nueva hipótesis con su propio nombre y darse cuenta de su personalidad científica ampliada en su triunfo.

La diferencia fundamental entre la solución moral y científica de un problema se encuentra en el hecho de que el problema moral trata con intereses personales concretos en los que la totalidad del sí-mismo es reconstruida en su relación con los otros sí-mismos, cuyas relaciones son esenciales para su personalidad. El crecimiento del sí-mismo emerge de una desintegración parcial -la aparición de distintos intereses en el foro de reflexión, la reconstrucción del mundo social y la consecuente aparición del nuevo sí-mismo que responde al nuevo objeto.
CÓMO CITAR ESTE ARTÍCULO

Mead, G. H. (1913/2018). El sí-mismo social [Trad. Miguel A. Sahagún y Anna Vitores]. Caleidoscopio. Revista Semestral de Ciencias Sociales y Humanidades, 22(39). DOI:10.33064/ 39 crsch 1540 